\title{
Androgens activate mitogen-activated protein kinase via epidermal growth factor receptor/insulin-like growth factor 1 receptor in the mouse PC-1 cell line
}

\author{
Mahsa Hamzeh ${ }^{\mathbf{1}}$ and Bernard Robaire ${ }^{\mathbf{1 , 2}}$ \\ ${ }^{1}$ Department of Pharmacology and Therapeutics, McGill University, McIntyre Medical Sciences Building, 3655 Promenade Sir-William-Osler, Room 104, \\ Montréal, Québec, Canada H3G 1 Y6 \\ ${ }^{2}$ Department of Obstetrics and Gynecology, McGill University Hospital Centre, 687 Pine Ave. West, Montréal, Québec, Canada H3A 1A1 \\ (Correspondence should be addressed to B Robaire at Department of Pharmacology and Therapeutics, McGill University; Email: bernard.robaire@mcgill.ca)
}

\begin{abstract}
Androgens are the primary regulators of epididymal structure and functions. In the classical view of androgen action, binding of androgen to the intracellular androgen receptor (AR) produces the receptor-steroid complex that has high affinity for DNA response elements and regulates the transcription of target genes. In this study, we demonstrate that in epididymal cells, $5 \alpha$-dihydrotestosterone (DHT) can cause an alternative and rapid response that is independent of AR-DNA interactions and is mediated by activation of signaling pathways through the AR. We examined changes in AKT and extracellular signal-regulated protein kinases (ERK1/2) activation at early time points after DHT supplementation in the mouse proximal caput epididymis-1 cell line. DHT had no significant effect on AKT activation at any time point. However, DHT activated the ERK pathway as early as at $1 \mathrm{~min}$, the pathway remained activated at $10 \mathrm{~min}$,
\end{abstract}

but activation was not sustained at later time points. Interestingly, ERK activation was blocked by hydroxyflutamide (HF), indicating that early ERK activation was an AR-mediated response. DHT phosphorylates steroid receptor co-activator (SRC) kinase, and this activation was required for the ERK response. EGFR and IGF1R were downstream of SRC, and these two receptors together contributed to enhance ERK and cAMP response elementbinding protein (CREB) phosphorylation. We postulate that this rapid action of androgen may ultimately act to modulate the transcription of genes regulated by AR in the nucleus. These results support the hypothesis that DHT can activate a pathway involving the sequential activation of MEK, ERK1/2, and CREB through the EGFR/IGF1R in an epididymal cell line.

Journal of Endocrinology (2011) 209, 55-64

\section{Introduction}

The epididymis plays an important role in male fertility, because it is the site where spermatozoa are matured and stored. Maturation of spermatozoa, including the acquisition of motility and capability to fertilize an oocyte, occurs during transit through the unique and dynamic microenvironment of the epididymal lumen. The specificity of the microenvironment is primarily under the influence of androgens that ultimately regulate epididymal cell structure and function (Orgebin-Crist 1967, Orgebin-Crist \& Tichenor 1973, Turner et al. 1984, Robaire \& Viger 1995). Principal cells are the major cell type of this tissue (Trasler et al. 1988) and are particularly sensitive to androgen removal (Moore \& Bedford 1979a,b). The major circulating androgen testosterone is metabolized by $5 \alpha$-reductases into the potent androgen $5 \alpha$-dihydrotestosterone (DHT; Gloyna \& Wilson 1969, Monsalve \& Blaquier 1977, Robaire et al. 1977). Androgens mediate their effects by diffusing through the plasma membrane and binding to intracellular androgen receptors
(ARs). The AR functions as a ligand-inducible transcription factor modulating transcription of target genes (He et al. 1999, Heinlein \& Chang 2002). In addition to this slow genomic action of androgens, several lines of evidence suggest that androgens, like progestins and estrogens, can exert rapid nongenomic effects (Christian et al. 2000, Falkenstein et al. 2000).

Unlike genomic effects that take hours or days to exert their action, non-genomic effects are activated within seconds or minutes (Sachs \& Leipheimer 1988, Crews \& Erikson 1993, Wehling 1997, Revelli et al. 1998, Christian et al. 2000, Falkenstein et al. 2000). The extracellular signal-regulated protein kinases (ERK1/2), members of the MAPK superfamily, are activated in response to androgens. These protein kinases play a key role in cell growth, differentiation, and function at both the transcriptional and the posttranscriptional levels, by phosphorylating a range of proteins, including nuclear transcription factors, cytoskeletal proteins, other protein kinases, and receptors for hormones and growth factors (Crews \& Erikson 1993, Nguyen et al. 2005, Gatson et al. 2006). Androgens can also activate the 
phosphatidylinositol-3 kinase (PI-3K) and AKT pathway rapidly in a ligand binding-independent manner (Lutz et al. 2003, Sun et al. 2003, Kang et al. 2004). However, it is unknown whether those two pathways, ERK1/2 and AKT, are activated in epididymal cells in response to DHT.

Studies have indicated that the non-genomic action of androgens depends on the ability of the AR to interact with the steroid receptor co-activator (SRC; Heinlein \& Chang 2002); activation of PI-3K by SRC family kinases has also been established (Liu et al. 1993). The androgen-AR complex interacts with the SH3 domain of SRC kinase and leads to a rapid activation of RAF-1 and MEK, and as a result, the ERK pathway; thus, the SRC-MAPK is one of the major routes in signal transduction (Migliaccio et al. 2000, Kousteni et al. 2001, Castoria et al. 2004, Cheng et al. 2007). Furthermore, SRC is also able to activate EGFR directly or indirectly and subsequently the MAPK pathway by phosphorylating tyrosine residues on the cytoplasmic face of EGFR (Stover et al. 1995); however, the role of IGF1R in mediating the rapid action of androgen through ERK pathway activation remains to be elucidated. Activation of SRC by androgen occurs only in the cell membrane, without the interaction of EGFR with AR, whereas EGFR, estrogen receptor, and SRC make a complex upon estrogen stimulation (Hitosugi et al. 2007).

In Sertoli cells, the rapid action of androgen leads to activation of transcription factors such as cAMP response element-binding protein (CREB); the latter is an essential factor required for Sertoli cells to support spermatogenesis (Fix et al. 2004, Cheng et al. 2007). Similarly, studies have shown that androgens upregulate the IGF1R by inducing CREB activation through activation of the c-SRC/ERK pathway in prostate cancer cells (Pandini et al. 2005, Genua et al. 2009), indicating the role of non-genomic action of androgens in regulation of gene transcription.

While several studies have established different pathways mediated by a non-genomic action of androgens, in this study we present an integrated model of an extranuclear, AR-mediated, rapid MAPK activation pathway that acts through the activation of EGFR/IGF1R signaling in an epididymal cell line.

\section{Materials and Methods}

\section{Cell culture and treatments}

The mouse proximal caput epididymis-1 (PC-1) cell line (kindly provided by Dr M-C Orgebin-Crist, Vanderbilt University) was derived from primary culture of epididymal cells from transgenic mice harboring a temperature-sensitive simian virus 40 large $\mathrm{T}$ antigen. It is a pure population of epithelium-derived caput principal cells (Araki et al. 2002). PC-1 cells were grown in Iscove's Modified Dulbecco's Medium (without phenol red) supplemented with $10 \%$ fetal bovine serum (FBS), $1 \mathrm{mM}$ sodium pyruvate, $0.1 \mathrm{mM}$ non-essential amino acids, $4 \mathrm{mM}$ glutamine,
$0 \cdot 7 \%$ penicillin-streptomycin (25 $000 \mathrm{U}$ penicillin sodium and $25 \mathrm{mg}$ streptomycin sulfate), and $1 \mathrm{nM} 5 \alpha$-DHT. All cell culture products were purchased from Wisent (St Bruno, QC, Canada), and DHT was from Steraloids, Inc. (Newport, RI, USA). PC-1 cells were cultured at $33{ }^{\circ} \mathrm{C}$ with $5 \% \mathrm{CO}_{2}$. FBS was replaced with charcoal-filtered FBS two passages before the experimental procedure, and the latter was used for the duration of the experiments. The cells were seeded onto flasks for 2,4 , and $6 \mathrm{~d}$ in the media as described above and subjected to vehicle as control or to different DHT concentration. Media were changed every $24 \mathrm{~h}$. Viability of the cells was determined by using trypan blue. Total RNA of the cells was then extracted. To assess the signaling activation, cells were seeded for $2 \mathrm{~d}$ in the media as described above. Proteins from the cells were extracted at various time points after changing the media. In some cases, cells were pretreated for $30 \mathrm{~min}$ with the signaling pathway inhibitors prior to being stimulated with DHT for $5 \mathrm{~min}$.

Inhibitors employed included hydroxyflutamide (HF; Toronto Research Chemicals, Inc., Toronto, ON, Canada), tyrphostin I-OMe-AG 538 (T7697, Sigma), tyrphostin AG 1478 (9842, Cell Signaling Technology, Beverly, MA, USA), and LY294002, PD98059 and PP2 were obtained from EMD Biochemicals (San Diego, CA, USA).

\section{$R N A$ extraction and DNase treatment}

Each experimental group comprised five different replicates. Total RNA was extracted and DNase treated using the RNeasy Mini kit (Qiagen) according to the manufacturer's instructions. RNA concentrations were assessed by OD determination at $260 \mathrm{~nm}$ (DU7 spectrophotometer, Beckman, Montreal, QC, Canada). The RNA used for microarray analysis had an A260/A280 ratio $>1 \cdot 8$. To verify the quality of each sample, $2 \mu \mathrm{g}$ RNA were run on a denaturing gel containing $1 \%$ agarose.

\section{Quantitative real-time PCR}

Quantitative real-time PCR was done using the LightCycler system (Roche Diagnostics) with the QuantiTect One-Step SYBR Green RT-PCR kit (Qiagen) according to the manufacturer's protocol. The specific primer sequences for Ar, Igf-1, and cyclophilin A (Ppia) were designed using Primer3 software (http://frodo.wi.mit.edu/cgi-bin/primer3/ primer3.cgi/). Cyclophilin $A$ was chosen as the endogenous control as its mRNA levels did not change with androgen manipulation (Palladino \& Hinton 1994). The primer sequences are as follows: cyclophilin $A$ : forward primer 5'-GTGGTCTTTGGGAAGGTGAA-3', reverse primer 5'-GTTGTCCACAGTCGGAGATG-3' (NM_008907); Ar: forward primer $5^{\prime}$-CAGGCAAAAGCACTGAAGAGA$3^{\prime}$, reverse primer $5^{\prime}$-GAGCCAGCGGAAAGTTGTAG-3' (NM_013476); Igf-1: forward primer 5'-GGCATTGTGGATGAGTGTTG-3', reverse primer $5^{\prime}$-GTCTTGGGCATGTCAGTGTG-3' (NM_178866). The PCR products 
were confirmed to be of appropriate size (128 for Igf- 1 and 216 for $A r)$. The specificity of the qRT-PCR primers was confirmed by melting curve analysis. Derivatives of the melting curves contained a single peak, indicating that a single PCR product has been generated; no primer-dimmers were observed. All standards and samples were assayed in duplicate. Average values for the target gene RNA concentrations of each sample were normalized to the average value for cyclophilin RNA concentration in the same sample.

\section{Western blot analysis}

Whole-cell extracts for each group were collected into lysis buffer containing protease and phosphatase inhibitors using the cellular fractionation kit (Cat. No: 40010) from Active Motif (Carlsbad, CA, USA), according to the manufacturer's protocol. We evaluated total protein concentration by the Bradford method, using the Bio-Rad protein assay (Bio-Rad Laboratories). Protein samples (15 $\mu$ g per group) were boiled with loading buffer for $5 \mathrm{~min}$ and fractionated by SDS-PAGE using 10\% acrylamide gels. Prestained precision standards (Bio-Rad Laboratories) were used as molecular weight markers. The fractionated proteins were transferred to a Hybond-P membrane (Amersham Biosciences UK). They were incubated with primary antibodies $(1: 1000$; unless stated otherwise), followed by HRP-conjugated second antibodies (1:10 000; Amersham Pharmacia Biotech UK).

The primary antibodies employed were against total MAP kinase 1/2 (ERK 1/2), CREB, and phospho-CREB (Ser ${ }^{133}$ ) (nos 06-182, 06-863, and 06-519, Millipore Corporation, Temecula, CA, USA), phospho-44/42 MAPK (ERK1/2) $\left(\mathrm{Thr}^{202} / \mathrm{Tyr}^{204}\right)$, total AKT (pan), and phospho-AKT $\left(\mathrm{Ser}^{473}\right)$ (nos 9106, 4691, and 4060, Cell Signaling Technology), a polyclonal antibody against phospho-SRC $\left[\mathrm{pY}^{418}\right]$ (44660G, Invitrogen Corporation), a monoclonal antibody against c-SRC (B-12) (sc-8056, Santa Cruz Biotechnology, Inc., Santa Cruz, CA, USA). The levels of P-ERK, P-AKT, P-SRC, and P-CREB were normalized to overall ERK, AKT, SRC, and CREB expression levels respectively. Actin (1:4000, sc-1616) was used as second loading control and was detected using a secondary, donkey anti-goat IgG HRP antibody (1:10 000, sc-2056). Western blots were visualized with the Enhanced Chemiluminescence Plus kit and Hyperfilm-Enhanced Chemiluminescence (Amersham Biosciences UK). Quantification of western blot data was done by line densitometry using a ChemiImager 4000 imaging system with AlphaEase (version 5.5 software; Alpha Innotech, San Leandro, CA, USA).

\section{Statistical analysis}

Statistical analysis was done using $t$-test or one-way ANOVA followed by the multiple comparisons Dunnett's test. Data were expressed as mean \pm s.E.M. Values of $P \leq 0.05$ were regarded as statistically significant.

\section{Results}

Cell viability is not affected by treatment

The effects of androgen withdrawal and treatment on cell viability were determined using the trypan blue staining technique. Cells did proliferate; the number of cells had doubled after $2 \mathrm{~d}$ and was increasing more slowly after $4 \mathrm{~d}$ (Supplementary Figure 1, see section on supplementary data given at the end of this article). Very few dead cells were observed within 6 days, although significant cell death was observed by $8 \mathrm{~d}$ after androgen withdrawal (data not shown).

\section{Ar and Igf1 genes are expressed in PC-1 cell line}

The mRNA expression of $A r$ and Igf1 genes was determined by qRT-PCR at 2,4 , and $6 \mathrm{~d}$ in androgen-deprived cells before and after DHT treatment. DHT had no significant effect on $A r$ expression in cells compared with that in vehicletreated cells (Supplementary Figure 2, see section on supplementary data given at the end of this article).
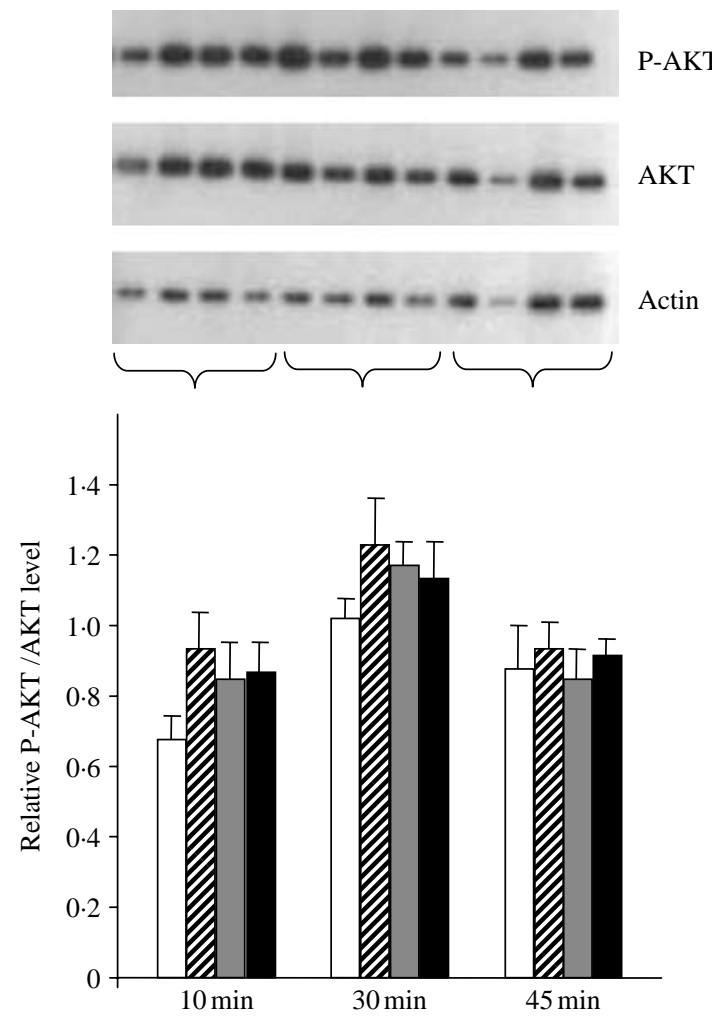

Figure 1 Effect of DHT on AKT activation. Cells were treated with vehicle (white bar) or DHT $(0 \cdot 1 \mathrm{Z}, 1 \mathrm{\square}$, and $10 \mathrm{nM}$ black bar) for 10, 30, or $45 \mathrm{~min}$. AKT phosphorylation was analyzed by western blot. Each bar represents the mean of five replicates \pm s.E.M. 
In comparison, Igf1 expression was significantly increased at 2, 4, and 6 days in DHT-treated cells compared with the control (Supplementary Figure 2, see section on supplementary data given at the end of this article).

\section{Activation of AKT and ERK1/2 by DHT}

To assess whether DHT can enhance the activation of the AKT or the ERK pathway, we stimulated cells with DHT $(0 \cdot 1,1$, or $10 \mathrm{nM})$ for 10,30 , or $45 \mathrm{~min}$. The amounts of phosphorylated AKT and ERK were measured relative to total AKT and ERK. DHT had no significant effect on AKT phosphorylation compared with control at any time point (Fig. 1). In contrast, DHT $(0 \cdot 1$ and $1 \mathrm{nM})$ significantly increased ERK phosphorylation at $10 \mathrm{~min}$; this activation was not sustained at 30 and $45 \mathrm{~min}$ (Fig. 2a). To determine whether this activation occurred earlier than $10 \mathrm{~min}$, ERK activation by $\operatorname{DHT}(0 \cdot 1$ and $1 \mathrm{nM})$ was investigated at 1,3 , and $5 \mathrm{~min}$. DHT significantly increased ERK phosphorylation levels compared with control at all time points (Fig. 2b). Similarly, AKT activation in response to DHT was also measured at earlier and later time points, but no significant changes were observed (data not shown). DHT did not alter total expression of AKT or ERK relative to actin.

\section{ERK1/2 is activated by DHT via an AR-mediated mechanism}

To determine the selectivity of DHT in stimulating ERK through an AR-mediated mechanism, cells were pretreated with $\mathrm{HF}$, a non-steroidal and reversible $\mathrm{AR}$ antagonist, before stimulation with $\operatorname{DHT}(0 \cdot 1,1$, or $10 \mathrm{nM})$. In order to see the complete effect of HF, the dose chosen was 1000-10 000 times higher concentration than that of DHT (Yamamoto et al. 2000, Urushibara et al. 2007). Pretreatment with HF repressed ERK phosphorylation significantly in DHT-treated cells compared with control. In cells without HF, treatment with $1 \mathrm{nM}$ DHT increased $\mathrm{p}$-ERK compared with control cells without HF, which is similar to the ratio between cells treated with and without $1 \mathrm{nM}$ DHT in the presence of HF that could be due to the blocking effect of HF on low endogenous androgen in cells or non-specific inhibitory effect of $\mathrm{HF}$ on cells. Interestingly, the repression of ERK phosphorylation by HF was partially reversed at higher DHT concentrations (Fig. 3). (a)
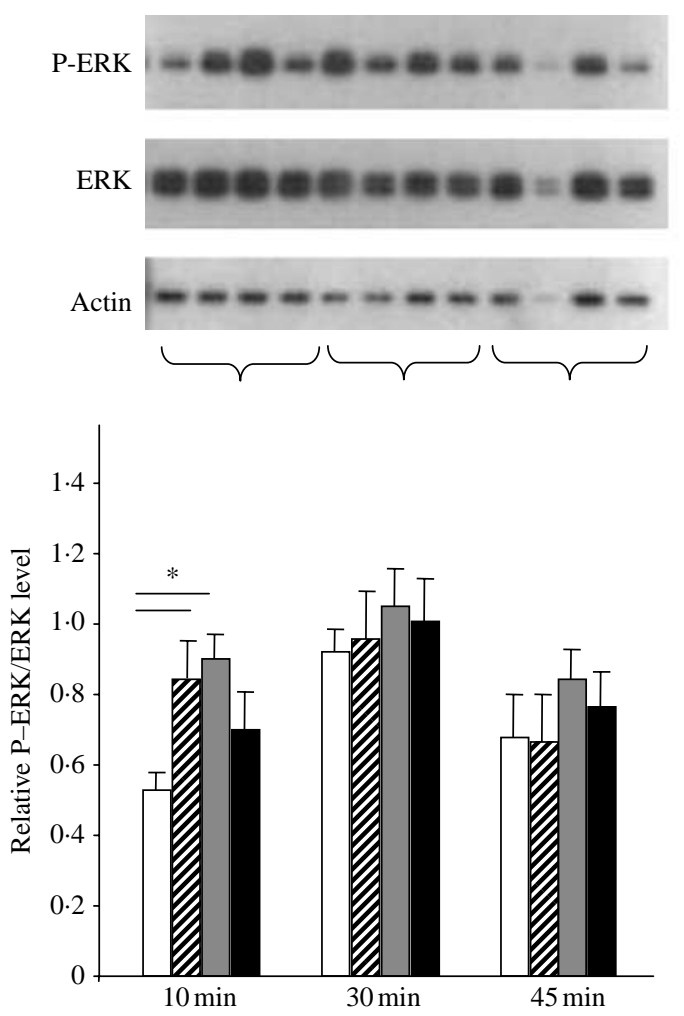

(b)
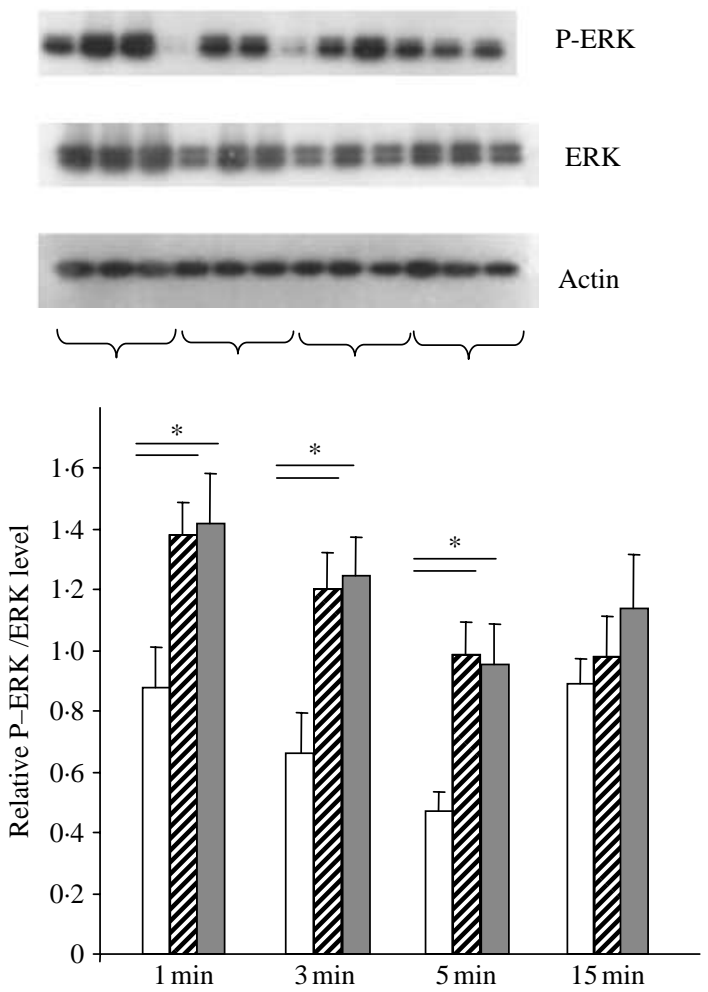

Figure 2 DHT elicits an increase in phospho-ERK1/2. (a) Cells were treated with vehicle (white bar) or DHT (0.1 $\mathbf{Z}, 1 \square$, and $10 \mathrm{nM}$ black bar) for 10, 30, or $45 \mathrm{~min}$. (b) Cells were treated with vehicle (white bar) or DHT (0.1 and $1 \mathrm{nM} \square)$ for 1, 3, 5, or 15 min. ERK phosphorylation was analyzed by western blot. $(*)$ Indicates that values were significantly different from vehicle-treated controls $(P \leq 0 \cdot 05)$. Each bar represents the mean of five replicates \pm s.E.M. 

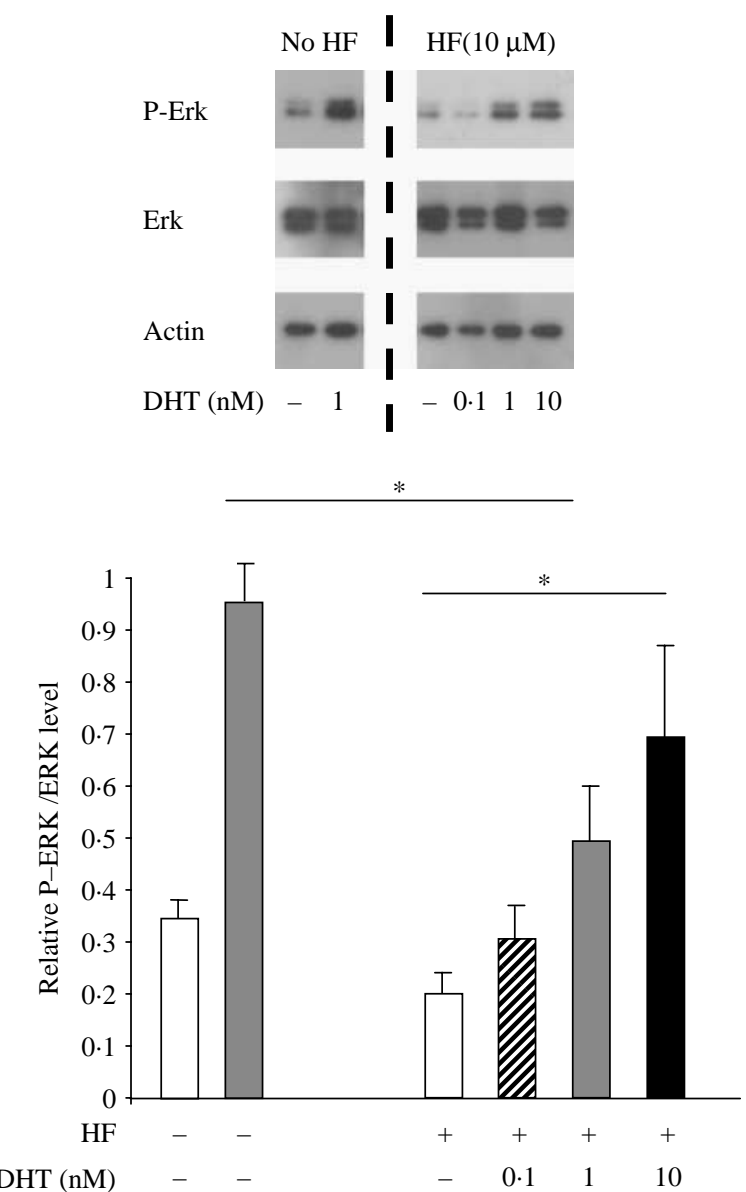

Figure 3 Hydroxyflutamide (HF) blocks DHT-induced ERK1/2 phosphorylation. Cells were pretreated for $30 \mathrm{~min}$ with hydroxyflutamide $(10 \mu \mathrm{M})$ before stimulation for $5 \mathrm{~min}$ with vehicle (white bar) or $\operatorname{DHT}(0 \cdot 1 \mathbb{Z}, 1 \square$, and $10 \mathrm{nM}$ black bar). ERK phosphorylation is shown by western blot. $\left(^{*}\right)$ Indicates that P-ERK was significantly repressed by HF compared with control, and this effect was reversed by increasing the concentration of DHT $(P \leq 0 \cdot 05)$. Each bar represents the mean of five replicates \pm S.E.M.

SRC kinase is phosphorylated by DHT and is required for ERK1/2 activation

We investigated the activation of c-SRC by DHT and found that DHT (1 nM) significantly increased SRC phosphorylation compared with control at 1 (data not shown) and $5 \mathrm{~min}$ (Fig. 4). Although it is possible that the activity of other SRC family members may be regulated by DHT, this result indicates that androgen stimulation results in a rapid phosphorylation of SRC in PC-1 cells. To assess whether SRC activation was required for DHT-mediated induction of ERK activation, cells were pretreated with PP2 before stimulation with DHT $(1 \mathrm{nM})$. ERK phosphorylation was significantly repressed by inhibition of SRC activation (Fig. 5). The inhibition of ERK phosphorylation by PP2, a
SRC specific inhibitor, was comparable to that of cells pretreated with MEK inhibitor, PD98059. In addition, ERK activation was significantly repressed by PI-3K inhibitor, LY294002 (Fig. 5). These results suggest that DHTdependent activation of ERK requires the activated SRC kinase, as well as PI-3K and MEK, the kinase that phosphorylates ERK. P-ERK was not significantly decreased with the lower concentration of inhibitors $(2.5 \mu \mathrm{M}$ LY and $\mathrm{PD}$, and $0.5 \mu \mathrm{M}$ PP2; data not shown).

\section{DHT activates the ERK pathway via IGF1R and EGFR}

To determine whether ERK is activated by DHT via IGF1R and EGFR, cells were pretreated with IGF1R inhibitor (AG1024), EGFR inhibitor (AG1478), and the combination of both inhibitors before stimulation with DHT $(1 \mathrm{nM})$. Increased ERK phosphorylation by DHT was significantly repressed by $25 \mu \mathrm{M}$ IGF1R inhibitor or $1 \mu \mathrm{M}$ EGFR inhibitor. Interestingly, using lower concentrations of the two inhibitors in combination, $10 \mu \mathrm{M}$ IGF1R inhibitor and $50 \mathrm{nM}$ EGFR inhibitor, ERK activation was significantly blocked, although at these concentrations each alone had no effect on the level of P-ERK (Fig. 6). These results suggest
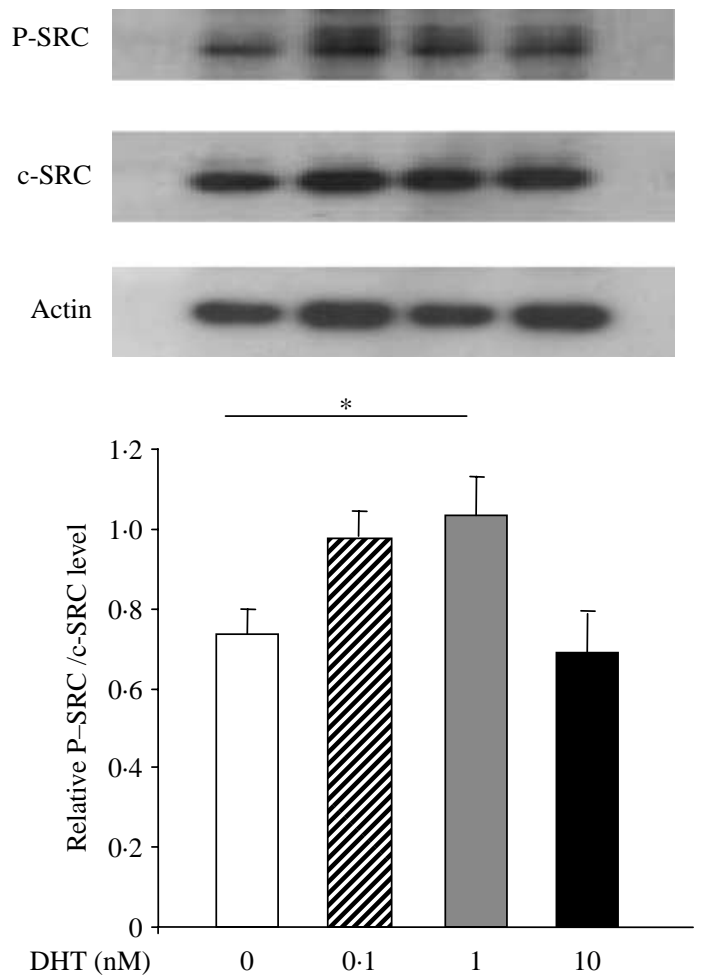

Figure 4 DHT induces SRC kinase activation. Cells were treated with vehicle (white bar) or DHT $(0 \cdot 1$, $1 \square$, and $10 \mathrm{nM}$ black bar) for $5 \mathrm{~min}$. Relative expression of SRC phosphorylation was analyzed by western blot. DHT (1 nM) significantly increased P-SRC compared with control $(* P \leq 0 \cdot 05)$. Each bar represents the mean of four replicates \pm S.E.M. 

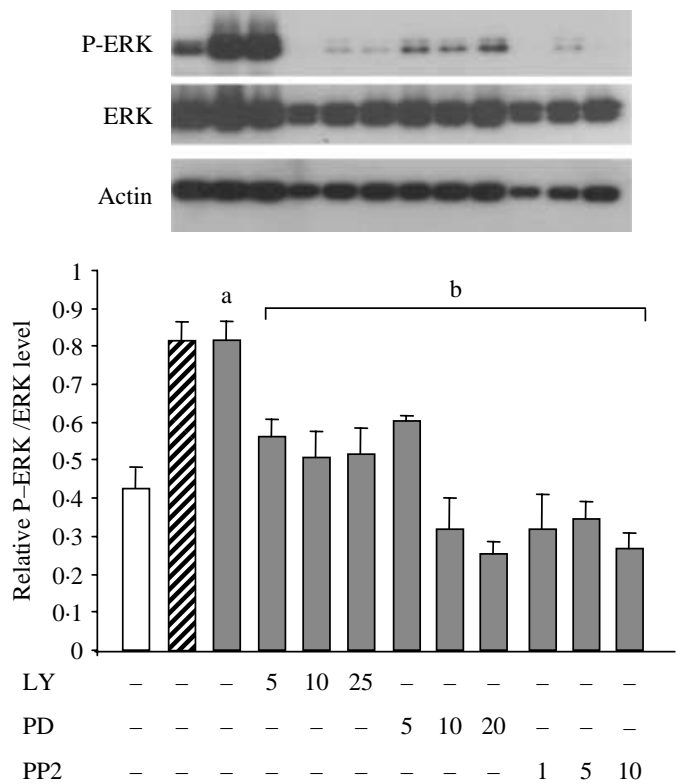

Figure 5 DHT-mediated induction of ERK1/2 requires SRC kinase. Cells were pretreated for $30 \mathrm{~min}$ with SRC inhibitor PP2 (1, 5, and $10 \mu \mathrm{M})$, MEK inhibitor PD98059 (5, 10, and $20 \mu \mathrm{M})$, or PI-3K inhibitor LY294002 (5, 10, and $25 \mu \mathrm{M})$ before stimulation for $5 \mathrm{~min}$ with vehicle (white bar) or DHT $(0 \cdot 1 \mathrm{Z}$ and $1 \mathrm{nM} \square)$. ERK phosphorylation was analyzed by western blot. The letter $\mathrm{b}$ indicates that values were significantly different $(P \leq 0 \cdot 05)$ compared with control value (a). Each bar represents the mean of four replicates \pm S.E.M.

that DHT mediates induction of ERK activation via IGF1R and EGFR and indicate that there is crosstalk between these two receptors.

\section{SRC acts upstream of IGF1R and EGFR}

To test whether the SRC kinase required for ERK phosphorylation was acting upstream of IGF1R and EGFR, cells were pretreated with inhibitors of IGF1R and EGFR alone or a combination of the two inhibitors prior to stimulation with DHT (1 $\mathrm{nM})$, and then SRC activation was assessed. The latter was not affected by IGF1R and EGFR inhibitors at any concentrations that repressed ERK phosphorylation (Supplementary Figure 3, see section on supplementary data given at the end of this article), suggesting that IGF1R and EGFR act downstream of SRC.

\section{Activation of ERK1/2 by DHT leads to CREB phosphorylation}

To ensure that increased ERK phosphorylation resulted in an increased activation of CREB, we tested whether there was an increase in the phosphorylation of CREB as a result of treatment with DHT and, if so, whether this increase was repressed by ERK inhibition. Cells were treated with vehicle or DHT $(0 \cdot 1$ or $1 \mathrm{nM})$ or were pretreated with a combination of IGF1R and EGFR inhibitors, before stimulation with DHT; P-CREB was assessed. DHT $(1 \mathrm{nM})$ significantly increased CREB phosphorylation (Fig. 7a), but this activation was partially repressed in cells pretreated with IGF1R and EGFR inhibitors (Fig. 7b). These results suggest that the activated ERK can stimulate transcription factors such as CREB.

\section{Discussion}

The results from these studies suggest that there is a mechanism for androgen action in epididymal epithelial cells that utilizes rapid activation of the MAP kinase pathway via IGF1R and EGFR and activation of CREB transcription factor. DHT increased IGF1 expression compared with the control, without having a mitogenic effect in the epididymal cells or killing them. Similar results for ERK activation have been observed in studies of breast cancer and prostate cancer cells, in which androgen activates the ERK pathway within minutes (Peterziel et al. 1999, Zhu et al. 1999). Androgeninduced phosphorylation of ERK1/2 occurred within 1 min

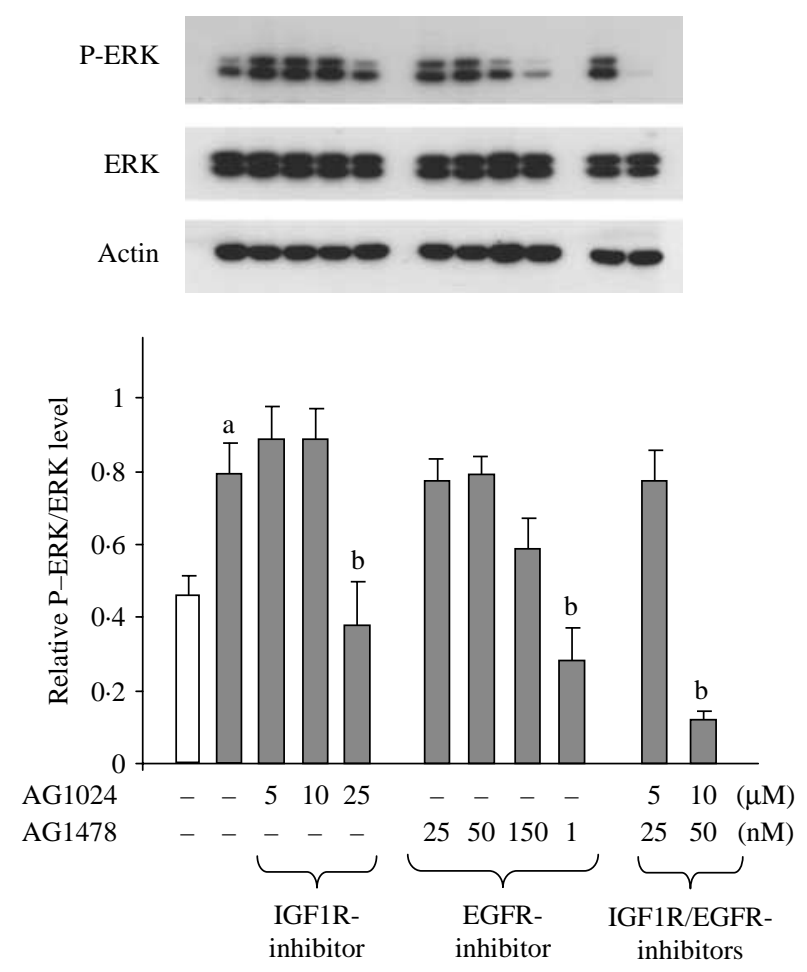

Figure 6 IGF-1R and EGFR inhibitors block P-ERK1/2. Cells were pretreated for $30 \mathrm{~min}$ with tyrphostin I-OMe-AG 538 (5, 10, and $25 \mu \mathrm{M})$ or tyrphostin AG $1478(25,50,150 \mathrm{nM}$, and $1 \mu \mathrm{M})$ before stimulation for $5 \mathrm{~min}$ with vehicle (white bar) or DHT (1 $\mathrm{nM})$. ERK phosphorylation was analyzed by western blot. The letter $b$ indicates that values were significantly different $(P \leq 0 \cdot 05)$ compared with control values (a). Each bar represents the mean of five replicates \pm S.E.M. 


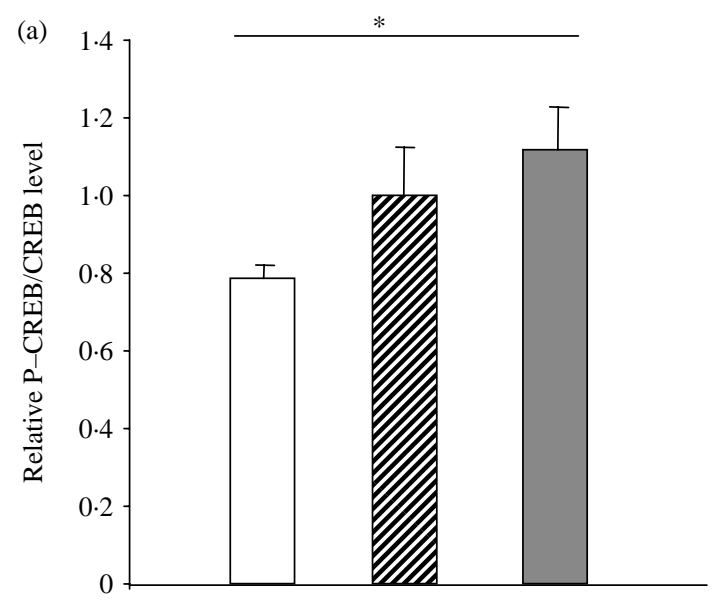

(b)

\section{P-CREB}
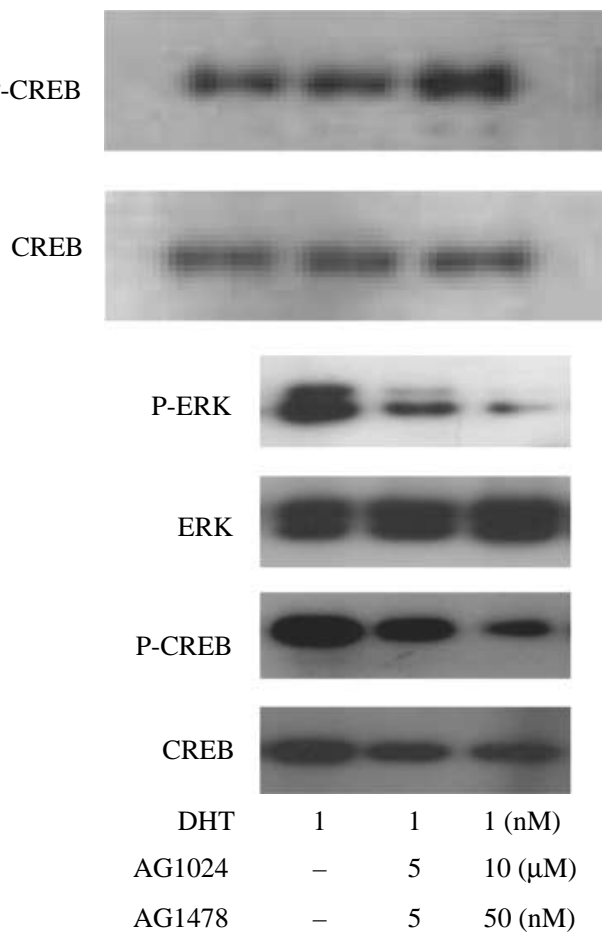

Figure 7 DHT induces CREB activation. (a) Cells were treated with vehicle (white bar) or DHT $(0 \cdot 1 \mathrm{~m}$ and $1 \mathrm{nM} \square)$ for $5 \mathrm{~min}$. CREB phosphorylation was analyzed by western blot. DHT (1 nM) significantly increased P-CREB compared with control $\left({ }^{*} P \leq 0 \cdot 05\right)$. Each bar represents the mean of four replicates \pm s.E.M. (b) Cells were pretreated for 30 min with IGF1R and EGFR inhibitors before stimulation for 5 min with DHT (1 nM) for 5 min. Inhibitors partially repressed P-CREB. The figure shown is representative of three experiments.

of androgen stimulation and was sustained for $10 \mathrm{~min}$. However, AKT phosphorylation was not altered upon androgen administration. Activation of ERK within minutes was repressed by reducing the activity of the AR, suggesting that this action occurred through an AR and was not mediated via binding of their cognate nuclear receptors to DNA, but rather through direct stimulation of cell signaling pathways. A schematic representation of the proposed pathway described in these studies is presented in Fig. 8.

The mechanism by which the androgen-AR complex initiates signaling in epididymal cells is not known. Recently, a population of $\mathrm{AR}$ has been localized to the plasma membrane in Sertoli cells, where testosterone rapidly and transiently promotes AR localization to the plasma membrane (Cheng et al. 2007). AR has also been localized to the plasma membrane in Xenopus oocytes and in hypothalamic cell lines (Shakil et al. 2002, Lutz et al. 2003). Association of AR with caveolin-containing membrane fractions is believed to facilitate interactions with their cognate ligands and shift the complex near membrane-associated signaling molecules, such as SRC kinase, PI-3K, or G proteins (Okamoto et al. 1998, Lu et al. 2001).

The non-receptor tyrosine kinase SRC is a major factor in signal transduction (Song et al. 2002, Razandi et al. 2003, Unni et al. 2004). We have shown that SRC is activated by $\mathrm{DHT}$ at $5 \mathrm{~min}$, and that it is required for ERK activation. The essential role of SRC kinase in the non-genomic action of ARs was demonstrated in studies on embryonic fibroblasts derived from $\mathrm{SRC}-/-$ mice in which the cells do not show rapid activation of the MAPK pathway in response to ligand binding to AR (Kousteni et al. 2001). In LNCaP prostate cells, androgen triggers the direct association of the prolinerich region of $\mathrm{AR}$ and the $\mathrm{SH} 3$ domain of SRC, causing the activation of SRC (Migliaccio et al. 2000); the latter is known

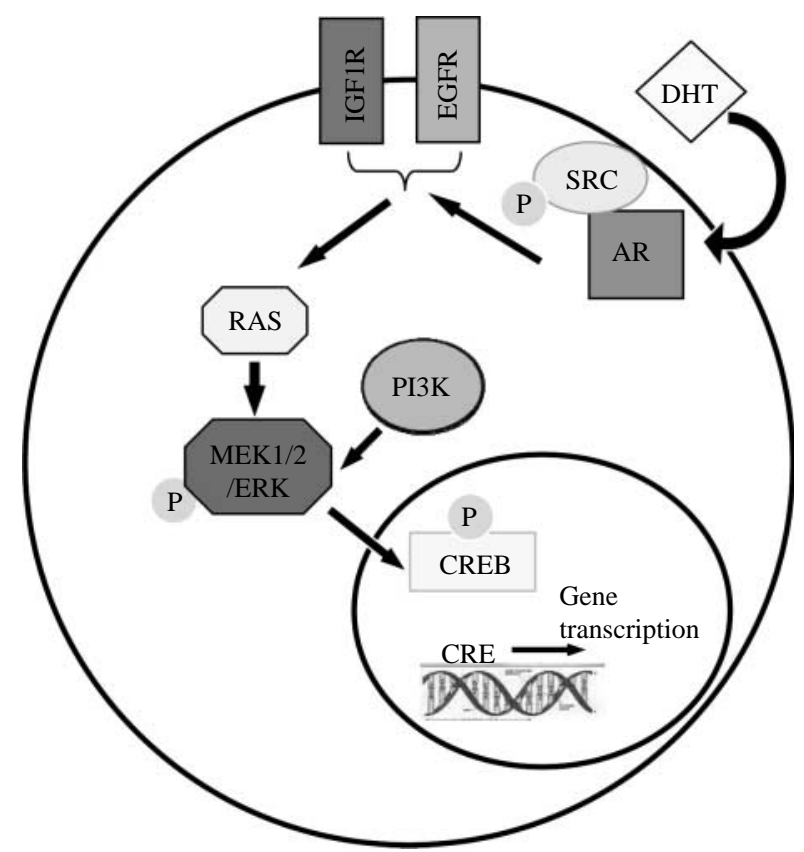

Figure 8 Signaling pathway activated by DHT in epididymal epithelial cells. DHT bound to the AR can activate a linear pathway involving the sequential activation of SRC, MEK, ERK1/2, and CREB through the EGFR/IGF1R in epididymal epithelial cells. 
to rapidly induce the formation of $\mathrm{Shc} / \mathrm{Grb} 2 / \mathrm{SOS}$ complexes, leading to the activation of RAS and subsequently stimulation of a RAF MAPK kinase kinase, the initial member of the MAPK pathway (Rusanescu et al. 1995). Activation of PI-3K by SRC kinase has been shown (Liu et al. 1993). Our data indicate that inhibition of PI-3K significantly reduces ERK1/2 activation.

The IGF and EGF ligands are mitogenic for both normal and tumorigenic mammary epithelial cells in vitro (Rosfjord \& Dickson 1999). The IGF1 and EGF receptors share a common molecular structure, with a cytoplasmic tail containing tyrosine residues; activation of these receptors ultimately leads to the activation of the PI-3K and MAPK signal transduction pathways (Baserga et al. 1997, Jorissen et al. 2003, Kolch 2005). SRC is capable of directly activating EGFR by phosphorylating tyrosine residues on the cytoplasmic face of EGFR and subsequently the MAPK pathway (Stover et al. 1995, Biscardi et al. 1999). Our finding identified the essential role of IGF1 and EGF receptors in DHT-induced ERK1/2 activation in epididymal epithelial cells. Using a combination of specific IGF1R and EGFR inhibitors, we observed a synergistic effect on blocking DHT-mediated phosphorylation of ERK. This effect further led to an increased phosphorylation of CREB transcription factor and presumably gene expression stimulation. CREB bound to cAMP response element motifs (TGACGTA) (Montminy et al. 1986, Benbrook \& Jones 1990) in gene promoters is able to associate with the binding protein coactivator that facilitates the recruitment of RNA polymerase to the transcription initiation site (Meyer \& Habener 1993, Kwok et al. 1994). For instance, CREB phosphorylation has been linked to the activation of numerous Sertoli cell genes that contribute to germ cell development and survival (Scobey et al. 2001), and upregulation of IGF1R in prostate cancer cells (Genua et al. 2009).

Taken together, these data identify a rapid signaling pathway that is activated by DHT stimulation in an epididymal epithelial cell line. This represents the first study in cells of the epididymis to report the upstream signaling components for ERK activation through the AR. While the results from this study demonstrate potential rapid signaling mechanisms by DHT in an epididymal cell line, further studies are required to establish the role of this pathway in vivo. Targeting this signaling pathway should be considered as a means of regulating androgen action, and hence function, in this tissue.

\section{Supplementary data}

This is linked to the online version of the paper at http://dx.doi.org/10.1530/ JOE-10-0223.

\section{Declaration of interest}

The authors declare that there is no conflict of interest that could be perceived as prejudicing the impartiality of the research reported.

\section{Funding}

These studies were supported by a grant MOP-86735 from the Canadian Institutes of Health Research (CIHR). M H is a recipient of a studentship from the McGill University Health Centre (MUHC).

\section{Acknowledgements}

We thank Marie-Claire Orgebin-Crist for providing us with the PC-1 cell lines. We are also grateful to Trang Luu for her technical assistance.

\section{References}

Araki Y, Suzuki K, Matusik RJ, Obinata M \& Orgebin-Crist MC 2002 Immortalized epididymal cell lines from transgenic mice overexpressing temperature-sensitive simian virus 40 large T-antigen gene. Journal of Andrology 23 854-869.

Baserga R, Hongo A, Rubini M, Prisco M \& Valentinis B 1997 The IGF-I receptor in cell growth, transformation and apoptosis. Biochimica et Biophysica Acta 1332 F105-F126.

Benbrook D \& Jones NC 1990 Heterodimer formation between CREB and JUN proteins. Oncogene 5 295-302.

Biscardi JS, Maa MC, Tice DA, Cox ME, Leu TH \& Parsons SJ 1999 c-SRCmediated phosphorylation of the epidermal growth factor receptor on Tyr845 and Tyr1101 is associated with modulation of receptor function. Journal of Biological Chemistry 274 8335-8343. (doi:10.1074/jbc.274.12. 8335)

Castoria G, Lombardi M, Barone MV, Bilancio A, Di DM, de FA, Varricchio L, Bottero D, Nanayakkara M, Migliaccio A et al. 2004 Rapid signalling pathway activation by androgens in epithelial and stromal cells. Steroids 69 517-522. (doi:10.1016/j.steroids.2004.05.001)

Cheng J, Watkins SC \& Walker WH 2007 Testosterone activates mitogenactivated protein kinase via SRC kinase and the epidermal growth factor receptor in Sertoli cells. Endocrinology 148 2066-2074. (doi:10.1210/en. 2006-1465)

Christian HC, Rolls NJ \& Morris JF 2000 Nongenomic actions of testosterone on a subset of lactotrophs in the male rat pituitary. Endocrinology 141 3111-3119. (doi:10.1210/en.141.9.3111)

Crews CM \& Erikson RL 1993 Extracellular signals and reversible protein phosphorylation: what to Mek of it all. Cell 74 215-217. (doi:10.1016/ 0092-8674(93)90411-I)

Falkenstein E, Norman AW \& Wehling M 2000 Mannheim classification of nongenomically initiated (rapid) steroid action(s). Journal of Clinical Endocrinology and Metabolism 85 2072-2075. (doi:10.1210/jc.85.5.2072)

Fix C, Jordan C, Cano P \& Walker WH 2004 Testosterone activates mitogenactivated protein kinase and the cAMP response element binding protein transcription factor in Sertoli cells. PNAS 101 10919-10924. (doi:10. 1073/pnas.0404278101)

Gatson JW, Kaur P \& Singh M 2006 Dihydrotestosterone differentially modulates the mitogen-activated protein kinase and the phosphoinositide 3-kinase/AKT pathways through the nuclear and novel membrane androgen receptor in C6 cells. Endocrinology 147 2028-2034. (doi:10.1210/ en.2005-1395)

Genua M, Pandini G, Sisci D, Castoria G, Maggiolini M, Vigneri R \& Belfiore A 2009 Role of cyclic AMP response element-binding protein in insulin-like growth factor-I receptor up-regulation by sex steroids in prostate cancer cells. Cancer Research 69 7270-7277. (doi:10.1158/00085472.CAN-09-0088)

Gloyna RE \& Wilson JD 1969 A comparative study of the conversion of testosterone to 17-beta-hydroxy-5-alpha-androstan-3-one (dihydrotestosterone) by prostate and epididymis. Journal of Clinical Endocrinology and Metabolism 29 970-977. (doi:10.1210/jcem-29-7-970)

He B, Kemppainen JA, Voegel JJ, Gronemeyer H \& Wilson EM 1999 Activation function 2 in the human androgen receptor ligand binding 
domain mediates interdomain communication with the $\mathrm{NH}(2)$-terminal domain. Journal of Biological Chemistry 274 37219-37225. (doi:10.1074/jbc. 274.52.37219)

Heinlein CA \& Chang C 2002 The roles of androgen receptors and androgenbinding proteins in nongenomic androgen actions. Molecular Endocrinology 16 2181-2187. (doi:10.1210/me.2002-0070)

Hitosugi T, Sasaki K, Sato M, Suzuki Y \& Umezawa Y 2007 Epidermal growth factor directs sex-specific steroid signaling through SRC activation. Journal of Biological Chemistry 282 10697-10706. (doi:10.1074/jbc. M610444200)

Jorissen RN, Walker F, Pouliot N, Garrett TP, Ward CW \& Burgess AW 2003 Epidermal growth factor receptor: mechanisms of activation and signalling. Experimental Cell Research 284 31-53. (doi:10.1016/S00144827(02)00098-8)

Kang HY, Cho CL, Huang KL, Wang JC, Hu YC, Lin HK, Chang C \& Huang KE 2004 Nongenomic androgen activation of phosphatidylinositol 3-kinase/AKT signaling pathway in MC3T3-E1 osteoblasts. Journal of Bone and Mineral Research 19 1181-1190. (doi:10.1359/JBMR.040306)

Kolch W 2005 Coordinating ERK/MAPK signalling through scaffolds and inhibitors. Nature Reviews. Molecular Cell Biology 6 827-837. (doi:10.1038/ nrm1743)

Kousteni S, Bellido T, Plotkin LI, O’Brien CA, Bodenner DL, Han L, Han K, DiGregorio GB, Katzenellenbogen JA, Katzenellenbogen BS et al. 2001 Nongenotropic, sex-nonspecific signaling through the estrogen or androgen receptors: dissociation from transcriptional activity. Cell 104 719-730. (doi:10.1016/S0092-8674(01)00268-9)

Kwok RP, Lundblad JR, Chrivia JC, Richards JP, Bachinger HP, Brennan RG, Roberts SG, Green MR \& Goodman RH 1994 Nuclear protein CBP is a coactivator for the transcription factor CREB. Nature 370 223-226. (doi:10.1038/370223a0)

Liu X, Marengere LE, Koch CA \& Pawson T 1993 The v-SRC SH3 domain binds phosphatidylinositol 3'-kinase. Molecular and Cellular Biology 13 5225-5232.

Lu ML, Schneider MC, Zheng Y, Zhang X \& Richie JP 2001 Caveolin-1 interacts with androgen receptor. A positive modulator of androgen receptor mediated transactivation. Journal of Biological Chemistry 276 13442-13451. (doi:10.1074/jbc.M006598200)

Lutz LB, Jamnongjit M, Yang WH, Jahani D, Gill A \& Hammes SR 2003 Selective modulation of genomic and nongenomic androgen responses by androgen receptor ligands. Molecular Endocrinology 17 1106-1116. (doi:10.1210/me.2003-0032)

Meyer TE \& Habener JF 1993 Cyclic adenosine 3',5'-monophosphate response element binding protein (CREB) and related transcriptionactivating deoxyribonucleic acid-binding proteins. Endocrine Reviews $\mathbf{1 4}$ 269-290. (doi:10.1210/edrv-14-3-269)

Migliaccio A, Castoria G, Di DM, de FA, Bilancio A, Lombardi M, Barone MV, Ametrano D, Zannini MS, Abbondanza C et al. 2000 Steroid-induced androgen receptor-oestradiol receptor beta-SRC complex triggers prostate cancer cell proliferation. EMBO Journal 19 5406-5417. (doi:10.1093/emboj/19.20.5406)

Monsalve A \& Blaquier JA 1977 Partial characterization of epididymal 5 alpha reductase in the rat. Steroids 30 41-51. (doi:10.1016/0039-128X (77) $90135-0)$

Montminy MR, Sevarino KA, Wagner JA, Mandel G \& Goodman RH 1986 Identification of a cyclic-AMP-responsive element within the rat somatostatin gene. PNAS 83 6682-6686. (doi:10.1073/pnas.83.18. 6682)

Moore HD \& Bedford JM 1979a Short-term effects of androgen withdrawal on the structure of different epithelial cells in the rat epididymis. Anatomical Record 193 293-311. (doi:10.1002/ar.1091930209)

Moore HD \& Bedford JM $1979 b$ The differential absorptive activity of epithelial cells of the rat epididymus before and after castration. Anatomical Record 193 313-327. (doi:10.1002/ar.1091930210)

Nguyen TV, Yao M \& Pike CJ 2005 Androgens activate mitogen-activated protein kinase signaling: role in neuroprotection. Journal of Neurochemistry 94 1639-1651. (doi:10.1111/j.1471-4159.2005.03318.x)
Okamoto T, Schlegel A, Scherer PE \& Lisanti MP 1998 Caveolins, a family of scaffolding proteins for organizing "preassembled signaling complexes" at the plasma membrane. Journal of Biological Chemistry 273 5419-5422. (doi:10.1074/jbc.273.10.5419)

Orgebin-Crist MC 1967 Sperm maturation in rabbit epididymis. Nature $\mathbf{2 1 6}$ 816-818. (doi:10.1038/216816a0)

Orgebin-Crist MC \& Tichenor PL 1973 Effect of testosterone on sperm maturation in vitro. Nature 245 328-329. (doi:10.1038/245328a0)

Palladino MA \& Hinton BT 1994 Expression of multiple gamma-glutamyl transpeptidase messenger ribonucleic acid transcripts in the adult rat epididymis is differentially regulated by androgens and testicular factors in a region-specific manner. Endocrinology 135 1146-1156. (doi:10.1210/en. 135.3.1146)

Pandini G, Mineo R, Frasca F, Roberts CT Jr, Marcelli M, Vigneri R \& Belfiore A 2005 Androgens up-regulate the insulin-like growth factor-I receptor in prostate cancer cells. Cancer Research 65 1849-1857. (doi:10.1158/0008-5472.CAN-04-1837)

Peterziel H, Mink S, Schonert A, Becker M, Klocker H \& Cato AC 1999 Rapid signalling by androgen receptor in prostate cancer cells. Oncogene 18 6322-6329. (doi:10.1038/sj.onc.1203032)

Razandi M, Alton G, Pedram A, Ghonshani S, Webb P \& Levin ER 2003 Identification of a structural determinant necessary for the localization and function of estrogen receptor alpha at the plasma membrane. Molecular and Cellular Biology 23 1633-1646. (doi:10.1128/MCB.23.5.1633-1646.2003)

Revelli A, Massobrio M \& Tesarik J 1998 Nongenomic actions of steroid hormones in reproductive tissues. Endocrine Reviews 193-17. (doi:10.1210/ er.19.1.3)

Robaire B \& Viger RS 1995 Regulation of epididymal epithelial cell functions. Biology of Reproduction 52 226-236. (doi:10.1095/biolreprod52. 2.226)

Robaire B, Ewing LL, Zirkin BR \& Irby DC 1977 Steroid delta4-5alphareductase and 3alpha-hydroxysteroid dehydrogenase in the rat epididymis. Endocrinology 101 1379-1390. (doi:10.1210/endo-101-5-1379)

Rosfjord EC \& Dickson RB 1999 Growth factors, apoptosis, and survival of mammary epithelial cells. Journal of Mammary Gland Biology and Neoplasia 4 229-237. (doi:10.1023/A:1018789527533)

Rusanescu G, Qi H, Thomas SM, Brugge JS \& Halegoua S 1995 Calcium influx induces neurite growth through a SRC-Ras signaling cassette. Neuron 15 1415-1425. (doi:10.1016/0896-6273(95)90019-5)

Sachs BD \& Leipheimer RE 1988 Rapid effect of testosterone on striated muscle activity in rats. Neuroendocrinology 48 453-458. (doi:10.1159/ 000125049)

Scobey M, Bertera S, Somers J, Watkins S, Zeleznik A \& Walker W 2001 Delivery of a cyclic adenosine $3^{\prime}, 5^{\prime}$-monophosphate response elementbinding protein (creb) mutant to seminiferous tubules results in impaired spermatogenesis. Endocrinology 142 948-954. (doi:10.1210/en.142.2.948)

Shakil T, Hoque AN, Husain M \& Belsham DD 2002 Differential regulation of gonadotropin-releasing hormone secretion and gene expression by androgen: membrane versus nuclear receptor activation. Molecular Endocrinology 16 2592-2602. (doi:10.1210/me.2002-0011)

Song RX, McPherson RA, Adam L, Bao Y, Shupnik M, Kumar R \& Santen RJ 2002 Linkage of rapid estrogen action to MAPK activation by ERalpha-Shc association and Shc pathway activation. Molecular Endocrinology 16 116-127. (doi:10.1210/me.16.1.116)

Stover DR, Becker M, Liebetanz J \& Lydon NB 1995 SRC phosphorylation of the epidermal growth factor receptor at novel sites mediates receptor interaction with SRC and P85 alpha. Journal of Biological Chemistry 270 15591-15597. (doi:10.1074/jbc.270.26.15591)

Sun M, Yang L, Feldman RI, Sun XM, Bhalla KN, Jove R, Nicosia SV \& Cheng JQ 2003 Activation of phosphatidylinositol 3-kinase/AKT pathway by androgen through interaction of p85alpha, androgen receptor, and SRC. Journal of Biological Chemistry 278 42992-43000. (doi:10.1074/jbc. M306295200)

Trasler JM, Hermo L \& Robaire B 1988 Morphological changes in the testis and epididymis of rats treated with cyclophosphamide: a quantitative approach. Biology of Reproduction 38 463-479. (doi:10.1095/biolreprod38. 2.463) 
Turner TT, Jones CE, Howards SS, Ewing LL, Zegeye B \& Gunsalus GL 1984 On the androgen microenvironment of maturing spermatozoa. Endocrinology 115 1925-1932. (doi:10.1210/endo-115-5-1925)

Unni E, Sun S, Nan B, McPhaul MJ, Cheskis B, Mancini MA \& Marcelli M 2004 Changes in androgen receptor nongenotropic signaling correlate with transition of LNCaP cells to androgen independence. Cancer Research 64 7156-7168. (doi:10.1158/0008-5472.CAN-04-1121)

Urushibara M, Ishioka J, Hyochi N, Kihara K, Hara S, Singh P, Isaacs JT \& Kageyama Y 2007 Effects of steroidal and non-steroidal antiandrogens on wild-type and mutant androgen receptors. Prostate 67 799-807. (doi:10. 1002/pros.20542)

Wehling M 1997 Specific, nongenomic actions of steroid hormones. Annual Review of Physiology 59 365-393. (doi:10.1146/annurev.physiol.59.1.365)
Yamamoto A, Hashimoto Y, Kohri K, Ogata E, Kato S, Ikeda K \& Nakanishi M 2000 Cyclin E as a coactivator of the androgen receptor. Journal of Cell Biology 150 873-879. (doi:10.1083/jcb.150.4.873)

Zhu X, Li H, Liu JP \& Funder JW 1999 Androgen stimulates mitogenactivated protein kinase in human breast cancer cells. Molecular and Cellular Endocrinology 152 199-206. (doi:10.1016/S0303-7207(99)00031-3)

Received in final form 5 January 2011

Accepted 10 January 2011

Made available online as an Accepted Preprint 10 January 2011 